\title{
Pancreatitis of biliary origin, optimal timing of cholecystectomy (PONCHO trial): study protocol for a randomized controlled trial
}

Stefan A Bouwense ${ }^{1}$, Marc G Besselink ${ }^{2,3,4}$, Sandra van Brunschot ${ }^{1}$, Olaf J Bakker ${ }^{2}$, Hjalmar C van Santvoort ${ }^{2}$, Nicolien J Schepers ${ }^{1}$, Marja A Boermeester ${ }^{4}$, Thomas L Bollen ${ }^{5}$, Koop Bosscha ${ }^{6}$, Menno A Brink ${ }^{7}$, Marco J Bruno ${ }^{8}$, Esther C Consten ${ }^{9}$, Cornelis H Dejong ${ }^{10}$, Peter van Duijvendijk ${ }^{11}$, Casper H van Eijck ${ }^{12}$, Jos J Gerritsen ${ }^{13}$, Harry van Goor ${ }^{14}$, Joos Heisterkamp ${ }^{15}$, Ignace H de Hingh ${ }^{16}$, Philip M Kruyt ${ }^{17}$, I Quintus Molenaar ${ }^{2}$, Vincent B Nieuwenhuijs ${ }^{18}$, Camiel Rosman ${ }^{19}$, Alexander F Schaapherder ${ }^{20}$, Joris J Scheepers ${ }^{21}$, Marcel BW Spanier ${ }^{22}$, Robin Timmer ${ }^{23}$, Bas L Weusten ${ }^{23}$, Ben J Witteman ${ }^{24}$, Bert van Ramshorst ${ }^{3}$, Hein G Gooszen', Djamila Boerma ${ }^{3^{*}}$ and for the Dutch Pancreatitis Study Group

\begin{abstract}
Background: After an initial attack of biliary pancreatitis, cholecystectomy minimizes the risk of recurrent biliary pancreatitis and other gallstone-related complications. Guidelines advocate performing cholecystectomy within 2 to 4 weeks after discharge for mild biliary pancreatitis. During this waiting period, the patient is at risk of recurrent biliary events. In current clinical practice, surgeons usually postpone cholecystectomy for 6 weeks due to a perceived risk of a more difficult dissection in the early days following pancreatitis and for logistical reasons. We hypothesize that early laparoscopic cholecystectomy minimizes the risk of recurrent biliary pancreatitis or other complications of gallstone disease in patients with mild biliary pancreatitis without increasing the difficulty of dissection and the surgical complication rate compared with interval laparoscopic cholecystectomy.
\end{abstract}

Methods/Design: PONCHO is a randomized controlled, parallel-group, assessor-blinded, superiority multicenter trial. Patients are randomly allocated to undergo early laparoscopic cholecystectomy, within 72 hours after randomization, or interval laparoscopic cholecystectomy, 25 to 30 days after randomization. During a 30-month period, 266 patients will be enrolled from 18 hospitals of the Dutch Pancreatitis Study Group. The primary endpoint is a composite endpoint of mortality and acute re-admissions for biliary events (that is, recurrent biliary pancreatitis, acute cholecystitis, symptomatic/obstructive choledocholithiasis requiring endoscopic retrograde cholangiopancreaticography including cholangitis (with/without endoscopic sphincterotomy), and uncomplicated biliary colics) occurring within 6 months following randomization. Secondary endpoints include the individual endpoints of the composite endpoint, surgical and other complications, technical difficulty of cholecystectomy and costs.

Discussion: The PONCHO trial is designed to show that early laparoscopic cholecystectomy (within 72 hours) reduces the combined endpoint of mortality and re-admissions for biliary events as compared with interval laparoscopic cholecystectomy (between 25 and 30 days) after recovery of a first episode of mild biliary pancreatitis. (Continued on next page)

\footnotetext{
*Correspondence: d.boerma@antoniusziekenhuis.nl

${ }^{3}$ Department of Surgery, St Antonius Hospital, PO 2500, Nieuwegein EM

3430, the Netherlands

Full list of author information is available at the end of the article
} 
(Continued from previous page)

Trial registration: Current Controlled Trials: ISRCTN72764151

Keywords: Acute pancreatitis, Gallstones, Trial, Common bile duct, Cholecystitis, Endoscopic retrograde cholangiopancreaticography, Surgery, Cholecystectomy, Timing, Mortality

\section{Background}

Acute pancreatitis is a major healthcare problem. The disease is the third most common gastrointestinal reason for acute hospital admission, carrying a mortality rate of $5 \%$ with a total annual cost of $\$ 2.2$ billion in the USA alone $[1,2]$. In most western countries approximately 30 to $55 \%$ of cases are caused by gallstones or sludge, referred to as biliary pancreatitis [3]. After biliary pancreatitis, patients may experience a recurrent episode of biliary pancreatitis or other biliary events, such as acute cholecystitis, common bile duct obstruction, cholangitis or biliary colics $[4,5]$. In order to prevent these recurrent biliary events, international guidelines advise performing cholecystectomy or endoscopic sphincterotomy (ES) after biliary pancreatitis [6,7]. Failure to provide definitive treatment exposes the patient to (potentially fatal) risks of biliary diseases [8].

The timing of cholecystectomy in patients with clinically severe pancreatitis, with local complications such as pancreatic necrosis and organ failure, is deliberately delayed until local complications have resolved, typically after some 6 weeks [9].

In patients with mild pancreatitis, international guidelines advise cholecystectomy directly after recovery or in the first 2 to 4 weeks after discharge for mild biliary pancreatitis $[4,6,7,10,11]$. However, there is no consensus on the ideal moment of cholecystectomy. Audits from Germany, the UK, the USA and Italy report that the majority of specialists perform an interval cholecystectomy 6 to 12 weeks after discharge, due to uncertainty about the efficacy and safety of an early cholecystectomy and for logistical reasons [12-15]. In a nationwide study in the Netherlands, we demonstrated that three-quarters of the patients admitted with mild biliary pancreatitis underwent cholecystectomy a median of 6 weeks after discharge [16]. Comparable results were found in a systematic review by our group where over $50 \%$ of patients underwent cholecystectomy at least 6 weeks after discharge [17].

Several nonrandomized studies in patients with mild biliary pancreatitis suggested that early cholecystectomy, as compared with interval cholecystectomy, prevents recurrent biliary pancreatitis or other complications of gallstone disease, without adding risks due to a more difficult surgical dissection in the early days following pancreatitis $[16,18]$. Because the current literature may be flawed by selection bias, a randomized study is needed to confirm that early cholecystectomy is indeed both superior to interval cholecystectomy and safe. The aim of this study is to investigate whether early laparoscopic cholecystectomy, within 72 hours after recovery of a first episode of mild biliary pancreatitis, as compared with interval laparoscopic cholecystectomy, 25 to 30 days after recovery, reduces mortality and acute re-admissions for biliary events.

\section{Methods/Design}

\section{Design}

The PONCHO trial is a randomized controlled, parallelgroup, assessor-blinded, superiority multicenter trial. Patients will be randomly allocated to receive early laparoscopic cholecystectomy, within 72 hours after randomization, or interval laparoscopic cholecystectomy, 25 to 30 days after randomization.

\section{Primary endpoint}

The primary endpoint is a composite endpoint of mortality and acute re-admissions for biliary events (that is, recurrent biliary pancreatitis, acute cholecystitis, symptomatic/obstructive choledocholithiasis requiring endoscopic retrograde cholangiopancreaticography (ERCP) including cholangitis (with/without ES), and uncomplicated biliary colics; see Table 1 for definitions) occurring within 6 months following randomization.

\section{Secondary endpoints}

We hypothesize that early laparoscopic cholecystectomy is both effective and safe and therefore included the following secondary endpoints to assess such an effect: individual endpoints of the composite endpoint; cholangitis (Table 2); number of biliary colics registered in patient diary; difficulty of cholecystectomy (scored by visual analog scale 0 to 10 ; 5 being averagely difficult); conversion to open cholecystectomy (measure of technical difficulty); total length of hospital stay; need for ICU admission and total length of ICU stay; and total direct and indirect costs.

\section{Safety endpoints}

The safety endpoints are: biliary leakage, Amsterdam types A to D (Table 2) [23]; need for additional surgical, radiological or endoscopic interventions [23]; other complications requiring treatment (that is, bacteremia or 
Table 1 Primary endpoint: definitions of biliary events

\begin{tabular}{|c|c|}
\hline Biliary event & Definition \\
\hline \multirow[t]{8}{*}{ Biliary pancreatitis } & Diagnosis of acute pancreatitis if at least two of the three following features are present [19]: \\
\hline & 1. Upper abdominal pain; \\
\hline & 2. Serum lipase or amylase levels above three times the upper level of normal; \\
\hline & 3. Characteristic findings of acute pancreatitis on cross-sectional abdominal imaging. \\
\hline & Biliary pancreatitis if one of the following definitions is present [20]: \\
\hline & 1. Gallstones and/or sludge diagnosed on imaging (transabdominal or endoscopic ultrasound or computed tomography); \\
\hline & $\begin{array}{l}\text { 2. In the absence of gallstones and/or sludge, a dilated common bile duct on ultrasound ( }>8 \mathrm{~mm} \text { in patients } \leq 75 \text { years old } \\
\text { or }>10 \mathrm{~mm} \text { in patients }>75 \text { years old); }\end{array}$ \\
\hline & $\begin{array}{l}\text { 3. The following laboratory abnormality: alanine aminotransferase (ALAT) level }>2 \text { times higher than normal values, } \\
\text { with ALAT >aspartate aminotransferase. }\end{array}$ \\
\hline \multirow[t]{12}{*}{ Acute cholecystitis } & Defined according to the 2007 Tokyo classification, grade I to III [21,22]. \\
\hline & A. Local signs of inflammation: \\
\hline & 1) Murphy's sign; \\
\hline & 2) RUQ mass/pain/tenderness. \\
\hline & B. Systemic signs of inflammation: \\
\hline & 1) Fever; \\
\hline & 2) Elevated C-reactive protein; \\
\hline & 3) Elevated white blood cell count. \\
\hline & C. Imaging findings characteristic of acute cholecystitis \\
\hline & Definite diagnosis \\
\hline & 1) One item in A and one item in B are positive; \\
\hline & 2) C confirms the diagnosis when acute cholecystitis is suspected clinically. \\
\hline Biliary colic & $\begin{array}{l}\text { Upper abdominal pain (either right upper quadrant or epigastric pain) lasting at least } 30 \text { minutes, according to the } \\
\text { Rome criteria [22]. }\end{array}$ \\
\hline
\end{tabular}

pneumonia); bleeding requiring reoperation or blood transfusion; and new-onset organ failure (Table 2).

\section{Study population}

All adult patients admitted with a first episode of biliary acute pancreatitis to one of the 18 participating hospitals of the Dutch Pancreatitis Study Group (listed in Authors' information) will be assessed for eligibility during their hospital admission. Potentially eligible patients are followed until eligibility is established 1 or 2 days before discharge from the hospital. If patients are classified as having mild biliary pancreatitis and fulfill all inclusion and exclusion criteria they are randomized (with a 1:1 ratio and stratified for hospital and ES) to undergo early

Table 2 Secondary endpoint: definitions

\begin{tabular}{|c|c|}
\hline Biliary event & Definition \\
\hline \multirow[t]{3}{*}{ Cholangitis } & All of the following features (as previously defined) [20]: \\
\hline & $\begin{array}{l}\text { 1) Serum total bilirubin level }>40 \mu \mathrm{mol} / \mathrm{l}(>2.3 \mathrm{mg} / \mathrm{dl}) \text { and/or dilated common bile duct ( }>6 \mathrm{~mm} \text { ) on transabdominal } \\
\text { or endoscopic ultrasound or computed tomography; }\end{array}$ \\
\hline & 2) Temperature $>38.5^{\circ} \mathrm{C}$. \\
\hline \multirow[t]{4}{*}{ Organ failure } & Failure of one or more of the following organ systems [19]: \\
\hline & 1) Respiratory: $\mathrm{PaO}_{2} \leq 60 \mathrm{mmHg}$ or need for mechanical ventilation; \\
\hline & 2) Cardiovascular: systolic blood pressure $<90$ mmHg or need for catecholamine support; \\
\hline & $\begin{array}{l}\text { 3) Renal: creatinine level }>177 \mu \mathrm{mol} / \mathrm{l} \text { after rehydration or need for hemofiltration or hemodialysis } \\
\text { (not including pre-existent renal failure). }\end{array}$ \\
\hline \multirow[t]{5}{*}{ Biliary leakage } & Defined according to the Amsterdam criteria [23]: \\
\hline & Type A: cystic duct leaks or leakage from aberrant or peripheral hepatic radicals; \\
\hline & Type B: major bile duct leaks with or without concomitant biliary strictures; \\
\hline & Type C: bile duct strictures without bile leakage; \\
\hline & Type D: complete transection of the duct with or without excision of some portion of the bile duct. \\
\hline
\end{tabular}


laparoscopic cholecystectomy or interval laparoscopic cholecystectomy (Figure 1).

\section{Inclusion criteria}

Inclusion criteria are: age $\geq 18$ years; diagnosis of acute pancreatitis (at least two of the three following features present [19]: upper abdominal pain; serum lipase or amylase levels above three times the upper level of normal; and characteristic findings of acute pancreatitis on cross-sectional abdominal imaging); mild pancreatitis (fulfilling both [19]: no pancreatic necrosis and/or peripancreatic collections; and no persistent (> 48 hours) organ failure (Table 2)); and biliary pancreatitis (any of the following three definitions [20,25-29]: gallstones and/or sludge diagnosed on imaging (transabdominal or endoscopic ultrasound or computed tomography); in the absence of gallstones and/or sludge, a dilated common bile duct on ultrasound ( $>8 \mathrm{~mm}$ in patients $\leq 75$ years old or $>10 \mathrm{~mm}$ in patients $>75$ years old); and alanine aminotransferase level $>2$ times higher than normal values, with serum alanine aminotransferase levels >aspartate aminotransferase level); and written informed consent.

\section{Exclusion criteria}

Exclusion criteria are: American Society of Anesthesiologists (ASA) III patients $>75$ years old; ASA IV and V patients; patients with ongoing alcohol abuse or chronic pancreatitis (males $>3$ units per day, females $>2$ units per day) [30]; or pregnancy.

\section{Time of randomization}

After eligibility has been confirmed and written informed consent has been obtained, randomization will take place when the following five discharge criteria are met: the treating physician anticipates that the patient can be discharged within 1 or 2 days; no need for opioid analgesics; declining C-reactive protein levels and $<100$ $\mathrm{mg} / \mathrm{l}$; no evidence of local or systemic complications (for example, no fever); and the patient has resumed oral intake.

\section{Randomization}

Randomization is possible 24 hours per day, 7 days per week and is performed centrally by the study coordinator using an Internet randomization module (Clinical Research Unit, Academic Medical Center, Amsterdam, the Netherlands). Randomization is stratified according to whether ES is performed and according to hospital.

Randomization is balanced for ES because ES has a protective effect on the occurrence of recurrent biliary pancreatitis and common bile duct obstruction [31]. This allows for subgroup analysis with or without ES. Randomization is balanced per hospital as treatment strategies, such as the use of intraoperative cholangiography, indication for enteral feeding and endoscopic sphincterotomy, may differ between hospitals.

Permuted-block randomization with varying block size is used and block size is concealed to all investigators involved in this study. Using this method it is impossible for investigators to predict the allocation of

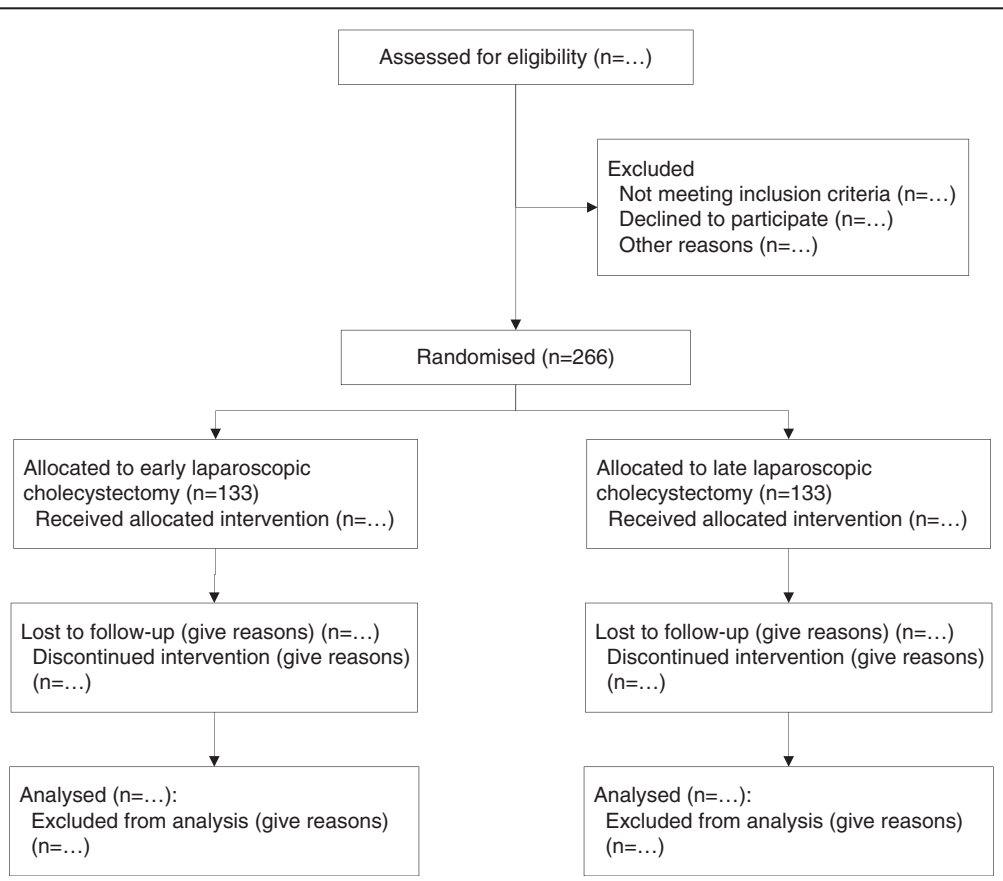

Figure 1 Flow of participants in the PONCHO trial. According to CONSORT [24]. 
trial participants. Concealing the allocation for investigators or trial participants is unfeasible due to the nature of this trial, because trial participants need to be scheduled for an early or interval cholecystectomy.

\section{Treatment protocol}

Group A received early laparoscopic cholecystectomy, within 72 hours after randomization (Figure 2).

As can be seen in the time of randomization criteria, patients will be randomized 1 or 2 days prior to discharge in an attempt to prevent prolonged hospital stay due to a waiting time for cholecystectomy.

Group B received interval laparoscopic cholecystectomy, 25 to 30 days after randomization (Figure 2).

\section{Surgical details and quality control}

Laparoscopic cholecystectomy will be performed according to the guidelines of the Dutch Society of Surgery, which include the critical view of safety technique [3234]. Patients are operated on by, or under the direct supervision of, a laparoscopically trained surgeon with $>100$ laparoscopic procedures performed in the previous 5 years. There has to be supervision during the entire procedure, from incision to skin closure.

Single port cholecystectomy will not be performed in this study because there is currently limited experience with this procedure in the Netherlands. If the treating physician decides to perform a primary open cholecystectomy (laparotomy or minilaparotomy), this is allowed in the trial.
Centers may only participate if they intend to randomize at least five patients in the study and are able to perform cholecystectomy $<72$ hours after randomization.

Given the excellent availability of ERCP/ES in the Netherlands and the lack of experience with intraoperative cholangiography, it is not mandatory to perform an intraoperative cholangiography and, if possible, transcystic stone extraction. In centers with sufficient experience, this technique is allowed. However, laparoscopic choledochal incision and exploration is not allowed as there is insufficient experience with this technique and it is likely to be associated with more morbidity than ERCP/ES. The following data regarding intraoperative cholangiography will be collected: incidence of choledocholithiasis, percentage stones retrieved transcystically, percentage bile duct injury, additional time required, and perceived difficulty (visual analog scale 0 to 10,5 being averagely difficult).

\section{Diagnosing and treating biliary pancreatitis}

For imaging, in the first 24 hours of admission all patients will undergo an abdominal ultrasound aimed at detecting gallstones and/or sludge in the gallbladder and at determining the diameter of the common bile duct.

Contrast-enhanced computed tomography (CECT) is only performed if the diagnosis for acute pancreatitis is unclear. CECT performed in the first 72 hours of acute pancreatitis cannot rule out necrotizing pancreatitis. Because $\mathrm{PONCHO}$ is a pragmatic trial and in current clinical practice CECT is not performed routinely in

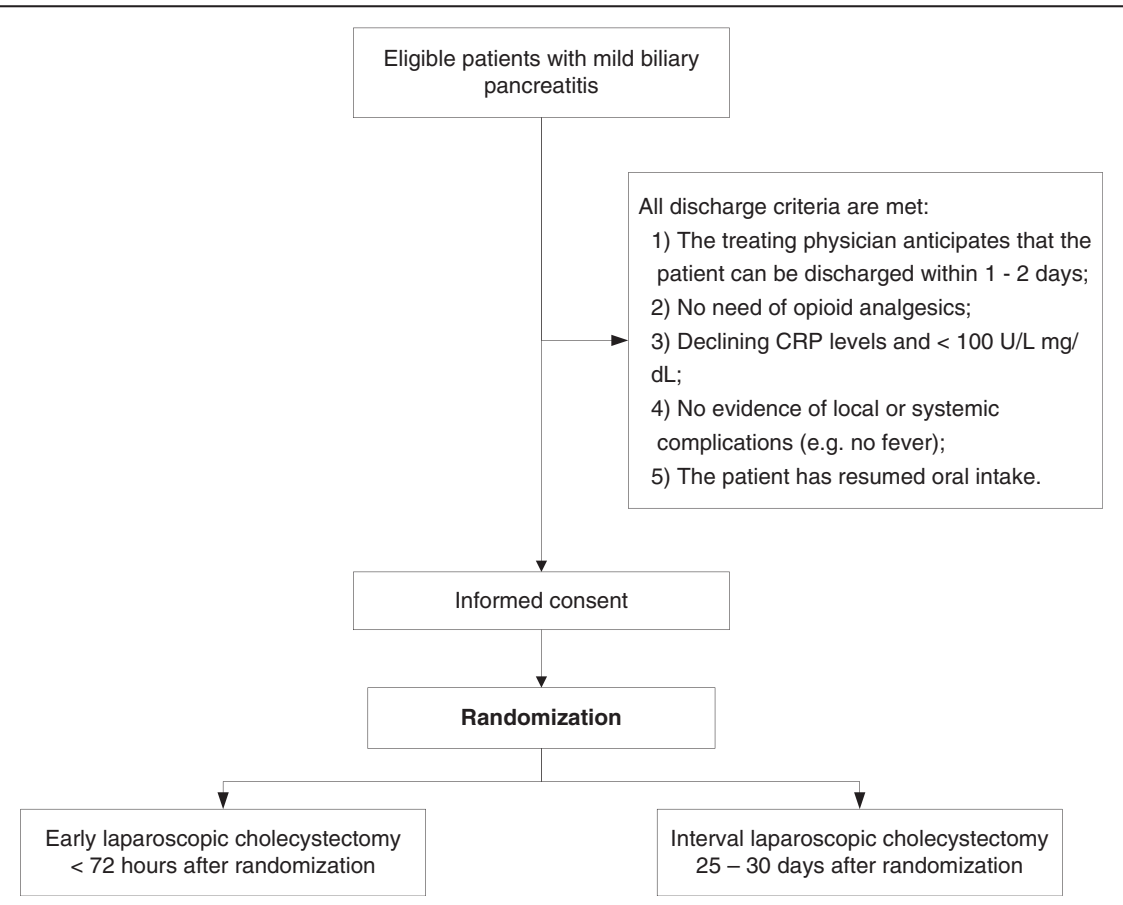

Figure 2 PONCHO overview of eligibility and group allocation. 
these patients, CECT is not scheduled for study purposes. CECT will be performed whenever dictated by clinical circumstances based on the judgment of the treating physicians. When the patient's condition does not improve after 1 week of hospital admission, CECT is performed to visualize the pancreas and abdomen.

ERCP/ES is performed when indicated by the treating physician.

Ursodeoxycholic acid therapy is not recommended after discharge since a recent Dutch randomized multicenter trial showed that this treatment is not effective in preventing recurrent colics and complications [35].

\section{Data collection and follow-up}

There will be telephone follow-up contacts at 3 and 6 months after randomization. When patients are readmitted to the hospital they are requested to contact the study coordinator. Patients are further asked to register biliary colics during the follow-up period in a gallstone diary. At 6 and 12 weeks after randomization, patients will be asked to complete the Health and Labour questionnaire [36]. Clinical data with regard to baseline characteristics and outcomes will be collected during hospital admission using a case record form. The case record form will be filled out by the local treating physicians, the study coordinator or the study nurse. The study coordinator and the study nurse are allowed to correct wrongly entered data (such as miscalculated patient age or miscalculated disease severity scores). The case record forms will be checked with source data. Only study group personnel will have access to the unblinded source data.

\section{Safety}

An independent Data and Safety Monitoring Committee (DSMC) will evaluate the progress of the trial and will examine safety variables. Every 30 patients, individualized patient description charts including unblinded safety parameters will be presented to the DSMC. In addition to the safety endpoints, death and (serious) adverse events, the incidence of biliary leakage, Amsterdam type D [23], will be of special interest. Extra monitoring of this severe complication is clinically important. The incidence of bile duct injury (Amsterdam types $\mathrm{A}$ to $\mathrm{D})$ has a range between 0.16 and $1.5 \%$ in the Netherlands [21].

After full explanation of the data presented by the investigators, the members of the DSMC will discuss the consequences of the data presented in the absence of the investigators. Adverse events are defined as 'any undesirable experience occurring to a subject during a clinical trial, whether or not considered related to the intervention' (that is, early cholecystectomy). All involved physicians will repetitively be asked to report any potential adverse events. These adverse events will be listed and discussed by the DSMC. The outcome of the meeting of the DSMC will then be discussed with the trial steering committee. The outcome will also be sent to the Institutional Review Board of the Radboud University Nijmegen Medical Centre. All possible severe adverse events will be reported to the Central Committee on Research involving Human Subjects (Centrale Commissie Mensgebonden Onderzoek) and the Institutional Review Board using the online module [37].

\section{Ethics}

The study will be performed in accordance with the declaration of Helsinki and the Dutch Wet Medischwetenschappelijk Onderzoek met Mensen (Medical Research Involving Human Subjects Act). The Institutional Review Board of the Radboud University Nijmegen Medical Centre approved the protocol on 22 July 2010. Secondary approval was sought from all local ethics committees. Informed consent will be obtained from each participating patient in oral and written form prior to randomization. The $\mathrm{PONCHO}$ trial is registered in the ISRCTN register with identification number ISRCTN72764151.

After approval of the protocol, three amendments were approved by the ethics board. These amendments followed new regulations in the Netherlands for the reporting of (serious) adverse events and minor protocol changes. The content of the amendments are incorporated in this protocol.

\section{Statistical aspects}

\section{Sample size calculation}

The PONCHO trial is a superiority trial, hypothesizing a reduction in the primary endpoint in favor of early cholecystectomy compared with the current practice of interval cholecystectomy. Data from our nationwide retrospective analysis on timing of cholecystectomy after mild biliary pancreatitis have been used to calculate the sample size [16,38]. In this previous analysis, $6.0 \%$ $(n=15)$ of 249 patients with mild biliary pancreatitis were re-admitted within 4 weeks after discharge for recurrent biliary problems prior to cholecystectomy, including 5\% recurrent biliary pancreatitis. Because this study was retrospective it might have missed several recurrent complications (arbitrarily set at 20\% missed endpoints: $0.2 \times 6 \%=1.2 \%)$. Furthermore, some $1 \%$ of patients may be re-admitted after cholecystectomy for recurrent biliary events. This amounts to an expected incidence of the primary endpoint in the interval laparoscopic cholecystectomy group of $8.2 \%(6.0+1.2+1.0)$. This number is quite conservative compared with the $10 \%$ re-admission rate within 4 weeks after mild biliary pancreatitis detected in our systematic review [17]. In 
the early laparoscopic cholecystectomy group, the readmission rate (primary endpoint) during 6 months follow-up is set at $1 \%$ since, similar to the interval group, patients may be re-admitted for recurrent biliary events.

To demonstrate a reduction of the primary endpoint from 8.2 to $1.0 \%$ with power $80 \%$ and two-sided alpha of $5 \%, 132$ patients will have to be included in each study group (PS Calculations, version 2.1.3; Vanderbilt University, Nashville, TN, USA). Taking a $0.5 \%(n=2)$ loss to follow-up (based on the previous PROPATRIA and PANTER trials [38,39]), a total of 266 patients will have to be randomized.

\section{Descriptive statistics}

For dichotomous data, frequencies will be presented. Continuous data will be presented as mean and standard deviation or median and interquartile range. Baseline characteristics (all prior to randomization) are: age, sex, body mass index, etiology of pancreatitis, ASA classification, co-morbidity (that is, cardiovascular disease, pulmonary disease, chronic renal insufficiency or diabetes), predicted severity (Acute Physiology and Chronic Health Evaluation II score, Imrie score and C-reactive protein), time from onset of symptoms to randomization, and time from onset of symptoms to cholecystectomy.

\section{Analyses}

All analyses will be by intention-to-treat, meaning that all randomized patients are included in their initially assigned study arm, regardless of adherence to study protocol. There will be a blinded outcome assessment after the last patient in the trial has completed the follow-up. An adjudication committee blinded for treatment allocation will evaluate each patient using the raw data for the possible occurrence of the primary endpoint. Disagreements will be resolved in a plenary consensus meeting.

The primary endpoint will be compared between the treatment groups and subsequent analyses are directed at the secondary and safety endpoints. To compare the safety and efficacy of both treatment strategies, all individual endpoints of the combined primary, secondary and safety endpoints will be taken together and compared between both treatment groups.

Results are presented as risk ratios with corresponding 95\% confidence intervals. Two-tailed $P<0.05$ is considered statistically significant with correction for multiple testing. In the event of imbalance between the two treatment groups a multivariable logistic regression will be used to correct for possible confounders. A post-hoc analysis will compare cholecystectomies with and without cholangiography.

\section{Additional analyses}

A predefined subgroup analysis will be performed on patients with or without ES, per center and age $(<75$ years vs. $>75$ years). We will use logistic regression models to perform a formal test for interaction to assess whether treatment effects differed significantly between these subgroups.

The costs of both treatment strategies for the whole follow-up period of 6 months will be compared. All costs will be estimated based on the actual input in terms of resource use, personnel and indirect costs from loss of productivity due to sick leave (assessed by the Health and Labour Questionnaire).

\section{Premature termination of the study}

In addition to assessing the safety of the patients in the study, the DSMC will check for early proof of efficacy during an interim analysis for benefit, which will be performed halfway through the study. The Peto approach will be followed, meaning that the study will only be stopped for beneficial effects in the event of $P<0.001$ [40]. The trial will not be stopped for futility, because this is the first randomized trial on this subject and treatment policy worldwide will be influenced by the results, regardless of the outcome.

If the DSMC suspects harm there will be a meeting between the DSMC, the steering committee and an independent statistician. During this meeting there should be a discussion about any potential causal relation between early cholecystectomy and harm based on the current literature.

The trial will be prematurely terminated if, after 4 years of inclusion, the required number of patients has not been reached, meaning a $60 \%$ delay in relation to the planned inclusion period of 2.5 years (30 months). Endpoints are not monitored sequentially.

\section{Publication policy}

All members of the steering committee and investigators involved in the daily logistics of the trial will be mentioned as an author.

For others, co-authorship will be based on the international guidelines, with a maximum of one co-author per participating site. Participating clinicians that do not fulfill these criteria will be listed as a collaborator and the journal will be asked to present the names of all collaborators to be listed in PubMed.

The order of authors will be based primarily on scientific input and secondarily on the number of randomized patients.

\section{Discussion}

The PONCHO trial is designed to answer the question of whether early cholecystectomy leads to a reduction of 
re-admissions for biliary events in patients with a first episode of mild biliary pancreatitis.

Several treatment guidelines state that cholecystectomy should be performed in the first weeks after recovery of mild biliary pancreatitis in order to minimize readmissions for biliary events $[4,6,7,10,11,16]$. In a systematic review we demonstrated that cholecystectomy should probably be performed during index admission because an early procedure was not associated with an increased risk of complications whereas interval cholecystectomy (after median 40 days) was associated with a biliary event recurrence rate of $18 \%$ [17]. In contrast to this finding, several nationwide audits from the UK, the USA, Germany and Italy have shown that most patients undergo cholecystectomy weeks or even months after discharge from the hospital for mild biliary pancreatitis [12-15]. As long as the gallbladder is in situ, these patients are at increased risk for re-admissions for biliary events including a potentially fatal episode of acute pancreatitis or other biliary events.

Why are surgeons not routinely performing early laparoscopic cholecystectomy after biliary pancreatitis? Early cholecystectomy may have three potential downsides: a technically more difficult and demanding procedure potentially resulting in more complications; poorer patient condition; and logistical hurdles.

Traditionally, early cholecystectomy has been suggested to be technically more demanding than interval cholecystectomy but data to support this statement are lacking. Notably, a recent study found that early cholecystectomy was technically less demanding, which is in keeping with the nature of peritoneal healing and adhesion formation [41]. This concept is supported by a recent retrospective study from India that focused on difficult dissection during laparoscopic cholecystectomy after mild biliary pancreatitis [18].

Traditionally, it is felt that patients should recover fully from pancreatitis prior to cholecystectomy being performed. However, the current study will only include patients with mild pancreatitis who are fit to undergo surgery. In contrast to severe pancreatitis, patients with mild pancreatitis recover quickly, and are discharged within 5 to 10 days after admission.

Problems with operating room capacity could arise due to the need for semi-urgent ( $<72$ hours) cholecystectomy. In the participating centers, however, dedicated operating room programs for semi-urgent surgery are present, and hence no major problems with protocol compliance are envisaged [41.

The only way to provide convincing, level I evidence that early cholecystectomy is indeed superior to interval cholecystectomy is to perform a randomized controlled trial. A double-blinded controlled trial would be the optimal design. However, due to the difference in timing of cholecystectomy, blinding is not possible. To compensate for this fact there will be a blinded outcome assessment.

A time interval of 72 hours was chosen for the early cholecystectomy group to provide a feasible time frame for semi-urgent cholecystectomy by an experienced surgeon. The 25-day to 30-day interval (4 weeks) was chosen as a trade-off between: the Dutch guideline that advices cholecystectomy within 3 weeks after discharge, and the data from our retrospective multicenter study demonstrating that cholecystectomy is delayed for 6 weeks in current Dutch clinical practice [16].

The rationale for including ASA I and II older people/ octogenarians is because several series have demonstrated that cholecystectomy is safe, even after ES, in older patients $[42,43]$. Patients with severe pancreatitis are excluded because this is considered an indication for delayed cholecystectomy [9].

For the proper timing of randomization we have chosen five discharge criteria that all have to be fulfilled in order to only include patients who are fit to undergo surgery and are without signs of severe pancreatitis. In contrast to severe pancreatitis, patients with mild pancreatitis recover quickly and are typically discharged within 5 to 10 days. There will be a variation in time since the onset of pancreatitis and hospital admission and between admission and discharge. This variation is mainly caused by co-morbidity. Owing to the randomization, there should be no relevant differences between both study arms.

The primary endpoint is a composite endpoint of mortality and re-admissions for biliary events. This composite endpoint was chosen because a study aimed at demonstrating a reduction in mortality only would require an unrealistic large sample size. In addition, other studies have shown that re-admissions for biliary events have much impact on the prognosis of patients [16].

The PONCHO trial is a randomized controlled multicenter trial designed to show a reduction in the composite primary endpoint of re-admissions for biliary events and mortality following an early cholecystectomy compared with an interval cholecystectomy in patients with a first episode of mild biliary pancreatitis.

\section{Trial status}

The trial was registered in the ISRCTN register on 29 June 2010. The first patient was randomized on 22 December 2010. As of 21 October 2012, 172 patients have been randomized and inclusion is on schedule.

\section{Abbreviations}

ASA: American Society of Anesthesiologists; CECT: contrast-enhanced Computed Tomography; DSMC: Data and Safety Monitoring Committee; ERCP: endoscopic retrograde cholangiopancreaticography; ES: endoscopic sphincterotomy; ISRCTN: International Standard Randomised Controlled Trial 
Number; PONCHO: Pancreatitis of biliary origin, optimal timing of cholecystectomy.

\section{Competing interests}

The authors declare that they have no competing interests.

\section{Authors' contributions}

SAB drafted the manuscript. MGB, SvB, OJB, HCvS, HGG, BvR and DB COauthored the writing of the manuscript. MGB, SAB, OJB, HCVS, AFS, VBN, BJW, $M A B, M J B, R T, B L W, H G G, B \vee R$ and DB participated in the design of the study during several meetings of the Dutch Pancreatitis Study Group. MGB and DB performed the sample size calculation. All authors critically assessed the study design or included patients in the study, edited the manuscript, and read and approved the final manuscript.

\section{Authors' information}

Steering committee: BL Weusten, R Timmer, MGH Besselink (also Academic Medical Center Amsterdam), B van Ramshorst, D Boerma (chair), St Antonius Hospital; HG Gooszen, SAW Bouwense, Radboud University Nijmegen Medical Centre; OJ Bakker, HC van Santvoort, University Medical Center Utrecht; AFM Schaapherder, Leiden University Medical Center; VB Nieuwenhuijs, University Medical Center Groningen; BJM Witteman, Hospital Gelderse Vallei Ede; MA Brink, Meander Medical Center; and MJ Bruno, Erasmus Medical Center.

Clinical centers (principal investigators) in the Netherlands (alphabetical order): Academic Medical Center, Amsterdam (MA Boermeester); CanisiusWilhelmina Hospital, Nijmegen (C Rosman); Catharina Hospital, Eindhoven (IHJT de Hingh); Erasmus Medical Center, Rotterdam (CH van Eijck); Gelre Hospital, Apeldoorn (P van Duijvendijk); Hospital Gelderse Vallei, Ede (Ph Kruyt) MD; Jeroen Bosch Hospital, Den Bosch (K Bosscha); Leiden University Medical Center, Leiden (AFM Schaapherder); Maastricht University Medical Center, Maastricht (CHC Dejong); Meander Medical Center, Amersfoort (EC Consten); Medical Spectre Twente, Enschede (JJGM Gerritsen); Radboud University Nijmegen Medical Center, Nijmegen (H van Goor); Reinier de Graaf Gasthuis, Delft (JJ Scheepers); Rijnstate Hospital, Arnhem (MB Spanier); St Antonius Hospital, Nieuwegein (D Boerma); St Elisabeth Hospital, Tilburg (J Heisterkamp); University Medical Center Groningen, Groningen (VB Nieuwenhuijs); and University Medical Center Utrecht, Utrecht (IQ Molenaar). Key staff at coordinating centers: St Antonius Hospital: MGH Besselink (also University Medical Center Utrecht and Academic Medical Center), B van Ramshorst and D Boerma (principal investigator); Radboud University Nijmegen Medical Centre: HG Gooszen, SAW Bouwense (study coordinator). DSMC: C Mulder, VU University Medical Center (chair); MA Cuesta, VU University Medical Center; AL Verbeek, Radboud University Nijmegen Medical Centre; AC Vahl, Onze Lieve Vrouwe Gasthuis.

Independent physician: AJPM Smout, Academic Medical Center, Amsterdam.

\section{Acknowledgements}

The Dutch Digestive Disease Foundation (Maag Lever Darm Stichting, grant number WO 11-03) financially supported the PONCHO trial. The sponsor had no influence on the design of the study; neither did they have any influence on the data collection, interpretation of results or the decision to publish.

\section{Author details}

'Department of OR/Evidence Based Surgery, Radboud University Nijmegen Medical Centre, HP 690, PO 9101, Nijmegen HB 6500, the Netherlands. ${ }^{2}$ Department of Surgery, University Medical Center Utrecht, HP G04.228, PO 85500, Utrecht GA 3508, the Netherlands. ${ }^{3}$ Department of Surgery, St Antonius Hospital, PO 2500, Nieuwegein EM 3430, the Netherlands. ${ }^{4}$ Department of Surgery, Academic Medical Center, PO 22660, Amsterdam DD 1100, the Netherlands. ${ }^{5}$ Department of Radiology, St Antonius Hospital, PO 2500, Nieuwegein EM 3430, the Netherlands. ' $D$ Department of Surgery, Jeroen Bosch Hospital, PO 90153, Den Bosch ME 5200, the Netherlands. ${ }^{7}$ Department of Gastroenterology, Meander Medical Center, PO 1502, Amersfoort BM 3800, the Netherlands. ${ }^{8}$ Department of Gastroenterology, Erasmus Medical Center, PO 2040, Rotterdam CA 3000, the Netherlands. ${ }^{9}$ Department of Surgery, Meander Medical Center, PO 1502, Amersfoort BM 3800, the Netherlands. ${ }^{10}$ Department of Surgery, Maastricht University Medical Center and NUTRIM School for Nutrition, Toxicology and Metabolism, PO 5800, Maastricht AZ 6202, the Netherlands. ${ }^{11}$ Department of Surgery, Gelre Hospital, PO 9014, Apeldoorn DS 7300, the Netherlands.
${ }^{12}$ Department of Surgery, Erasmus Medical Center, PO 2040, Rotterdam, CA 3000, the Netherlands. ${ }^{13}$ Department of Surgery, Medisch Spectrum Twente, PO 50000, Enschede KA 7500, the Netherlands. ${ }^{14}$ Department of Surgery, Radboud University Nijmegen Medical Centre, HP 690, PO 9101, Nijmegen HB 6500, the Netherlands. ${ }^{15}$ Department of Surgery, St. Elisabeth Hospital, PO 90151, Tilburg, LC 5000, the Netherlands. ${ }^{16}$ Department of Surgery, Catharina Hospital, PO 1350, Eindhoven EJ 5623, the Netherlands. ${ }^{17}$ Department of Surgery, Hospital Gelderse Vallei Ede, PO 9025, Ede HN 6710, the Netherlands. ${ }^{18}$ Department of Surgery, University Medical Center Groningen, PO 30001, Groningen RB 9700, the Netherlands. ${ }^{19}$ Department of Surgery, Canisius-Wilhelmina Hospital, PO 9015, Nijmegen GS 6500, the Netherlands. ${ }^{20}$ Department of Surgery, Leiden University Medical Center, PO 9600, Leiden, RC 2300, the Netherlands. ${ }^{21}$ Department of Surgery, Reinier de Graaf Gasthuis, PO 5011, Delft AD 2625, the Netherlands. ${ }^{22}$ Department of Gastroenterology, Rijnstate Hospital, PO 9555, Arnhem TA 6800, the Netherlands. ${ }^{23}$ Department of Gastroenterology, St Antonius Hospital, PO 2500, Nieuwegein EM 3430, the Netherlands. ${ }^{24}$ Department of Gastroenterology, Hospital Gelderse Vallei Ede, PO 9025, Ede HN 6710, the Netherlands.

Received: 3 June 2012 Accepted: 22 October 2012

\section{Published: 26 November 2012}

\section{References}

1. Shaheen NJ, Hansen RA, Morgan DR, Gangarosa LM, Ringel Y, Thiny MT, Russo MW, Sandler RS: The burden of gastrointestinal and liver diseases, 2006. Am J Gastroenterol 2006, 101:2128-2138.

2. Fagenholz PJ, Fernandez-del Castillo C, Harris NS, Pelletier AJ, Camargo CA: Direct medical costs of acute pancreatitis hospitalizations in the United States. Pancreas 2007, 35:302-307.

3. Yadav D, Lowenfels AB: Trends in the epidemiology of the first attack of acute pancreatitis: a systematic review. Pancreas 2006, 33:323-330.

4. UK Working Party on Acute Pancreatitis: UK guidelines for the management of acute pancreatitis. Gut 2005, 54(Suppl 3):iii1-iii9.

5. Forsmark CE, Baillie J: AGA institute technical review on acute pancreatitis. Gastroenterology 2007, 132:2022-2044.

6. Banks PA, Freeman ML: Practice guidelines in acute pancreatitis. Am J Gastroenterol 2006, 101:2379-2400.

7. Uhl W, Warshaw A, Imrie C, Bassi C, McKay CJ, Lankisch PG, Carter R, Di Magno E, Banks PA, Whitcomb DC, Dervenis C, Ulrich CD, Satake K, Ghaneh P, Hartwig W, Werner J, McEntee G, Neoptolemos JP, Büchler MW, International Association of Pancreatology: IAP Guidelines for the Surgical Management of Acute Pancreatitis. Pancreatology 2002, 2:565-573.

8. Gullo L, Migliori M, Pezzilli R, Olah A, Farkas G, Levy P, Arvanitakis C, Lankisch $P$, Beger $\mathrm{H}$ : An update on recurrent acute pancreatitis: data from five European countries. Am J Gastroenterol 2002, 97:1959-1962.

9. Nealon WH, Bawduniak J, Walser EM: Appropriate timing of cholecystectomy in patients who present with moderate to severe gallstone-associated acute pancreatitis with peripancreatic fluid collections. Ann Surg 2004, 239:741-749.

10. Nederlandse Internisten Vereniging: Richtlijn Acute Pancreatitis.; www.pancreatitis.nl.

11. Toouli J, Brooke-Smith M, Bassi C, Carr-Locke D, Telford J, Freeny P, Imrie C, Tandon R: Guidelines for the management of acute pancreatitis. J Gastroenterol Hepatol 2002, 17(Suppl 1):15-39.

12. Lankisch PG, Weber-Dany B, Lerch MM: Clinical perspectives in pancreatology: compliance with acute pancreatitis guidelines in Germany. Pancreatology 2005, 5:591-593.

13. Monkhouse SJ, Court EL, Dash I, Coombs NJ: Two-week target for laparoscopic cholecystectomy following gallstone pancreatitis is achievable and cost neutral. Br J Surg 2009, 96:751-755.

14. Nguyen GC, Boudreau H, Jagannath SB: Hospital volume as a predictor for undergoing cholecystectomy after admission for acute biliary pancreatitis. Pancreas 2010, 39:e42-e47.

15. Pezzilli R, Uomo G, Gabbrielli A, Zerbi A, Frulloni L, De Rai P, Castoldi L, Cavallini G, Di Carlo V: A prospective multicentre survey on the treatment of acute pancreatitis in Italy. Dig Liver Dis 2007, 39:838-846.

16. Bakker OJ, van Santvoort HC, Hagenaars JC, Besselink MG, Bollen TL, Gooszen HG, Schaapherder AF: Dutch Pancreatitis Study Group: Timing of cholecystectomy after mild biliary pancreatitis. Br J Surg 2011, 98:1446-1454. 
17. van Baal MC, Besselink MG, Bakker OJ, van Santvoort HC, Schaapherder AF, Nieuwenhuijs VB, Gooszen HG, van Ramshorst B, Boerma D: Dutch Pancreatitis Study Group: timing of cholecystectomy after mild biliary pancreatitis: a systematic review. Ann Surg 2012, 255:860-866.

18. Sinha R: Early laparoscopic cholecystectomy in acute biliary pancreatitis: the optimal choice? HPB (Oxford) 2008, 10:332-335.

19. Banks PA, Bollen TL, Dervenis C, Gooszen HG, Johnson CD, Sarr MG, Tsiotos GG, Vege SS, Acute Pancreatitis Classification Working Group: Classification of acute pancreatitis-2012: revision of the Atlanta classification and definitions by international consensus. Gut 2012,

20. van Santvoort HC, Besselink MG, de Vries AC, Boermeester MA, Fischer K, Bollen TL, Cirkel GA, Schaapherder AF, Nieuwenhuijs VB, van Goor H, Dejong $\mathrm{CH}$, van Eijck $\mathrm{CH}$, Witteman $\mathrm{BJ}$, Weusten $\mathrm{BL}$, van Laarhoven $\mathrm{CJ}$, Wahab PJ, Tan AC, Schwartz MP, van der Harst E, Cuesta MA, Siersema PD, Gooszen HG, van Erpecum KJ, Dutch Acute Pancreatitis Study Group: Early endoscopic retrograde cholangiopancreatography in predicted severe acute biliary pancreatitis: a prospective multicenter study. Ann Surg 2009, 250:68-75.

21. Keus F, de Jong JA, Gooszen HG, van Laarhoven CJ: Laparoscopic versus open cholecystectomy for patients with symptomatic cholecystolithiasis 904. Cochrane Database Syst Rev 2006, 4:CD006231.

22. Mayumi T, Takada T, Kawarada Y, Nimura Y, Yoshida M, Sekimoto M, Miura F, Wada K, Hirota M, Yamashita Y, Nagino M, Tsuyuguchi T, Tanaka A, Gom H, Pitt HA: Results of the Tokyo Consensus Meeting Tokyo Guidelines. $J$ Hepatobiliary Pancreat Surg 2007, 14:114-121.

23. Bergman JJ, van den Brink GR, Rauws EA, de Wit L, Obertop H, Huibregtse K, Tytgat GN, Gouma DJ: Treatment of bile duct lesions after laparoscopic cholecystectomy. Gut 1996, 38:141-147.

24. Schulz KF, Altman DG, Moher D: CONSORT 2010 statement: updated guidelines for reporting parallel group randomised trials. BMJ 2010, 340:c332.

25. Ammori BJ, Boreham B, Lewis $P$, Roberts SA: The biochemical detection of biliary etiology of acute pancreatitis on admission: a revisit in the modern era of biliary imaging. Pancreas 2003, 26:e32-e35.

26. Levy P, Boruchowicz A, Hastier P, Pariente A, Thevenot T, Frossard JL, Buscail L, Mauvais F, Duchmann JC, Courrier A, Bulois P, Gineston JL, Barthet M, Licht H, O'Toole D, Ruszniewski P: Multicentre prospective evaluation of 213 patients. Pancreatology 2005, 5:450-456.

27. Tenner S, Dubner $H$, Steinberg W: Predicting gallstone pancreatitis with laboratory parameters: a meta-analysis. Am J Gastroenterol 1994, 89:1863-1866

28. Neoptolemos JP, Carr-Locke DL, London NJ, Bailey IA, James D, Fossard DP: Controlled trial of urgent endoscopic retrograde cholangiopancreatography and endoscopic sphincterotomy versus conservative treatment for acute pancreatitis due to gallstones. Lancet 1988, 2:979-983.

29. Folsch UR, Nitsche R, Ludtke R, Hilgers RA, Creutzfeldt W: Early ERCP and papillotomy compared with conservative treatment for acute biliary pancreatitis. N Engl J Med 1997, 336:237-242.

30. White IR, Altmann DR, Nanchanal K: Alcohol consumption and mortality: modelling risks for men and women at different ages. BMJ 2002, 325:191-194.

31. van Geenen EJ, van der Peet DL, Mulder CJ, Cuesta MA, Bruno MJ: Recurrent acute biliary pancreatitis: the protective role of cholecystectomy and endoscopic sphincterotomy. Surg Endosc 2009, 23:950-956.

32. Strasberg SM, Hertl M, Soper NJ: An analysis of the problem of biliary injury during laparoscopic cholecystectomy. J Am Coll Surg 1995, 180:101-125.

33. Tonouchi H, Ohmori Y, Kobayashi M, Kusunoki M: Trocar site hernia. Arch Surg 2004, 139:1248-1256.

34. Lange JF, Stassen LPS: Best Practice: De techniek van de laparoscopische cholecystectomie (Critical View of Safety [CVS]; Werkgroep Endoscopische Chirurgie van de Nederlandse Vereniging voor Heelkunde). 2006. 2006.

35. Venneman NG, Besselink MG, Keulemans YC, van Berge-Henegouwen GP, Boermeester MA, Broeders IA, Go PM, van Erpecum KJ: Ursodeoxycholic acid exerts no beneficial effect in patients with symptomatic gallstones awaiting cholecystectomy. Hepatology 2006, 43:1276-1283.

36. van Roijen L, Essink-Bot ML, Koopmanschap MA, Bonsel G, Rutten FF: Labor and health status in economic evaluation of health care. The Health and Labor Questionnaire. Int J Technol Assess Health Care 1996, 12:405-415.
37. ToetsingOnline: https://toetsingonline.ccmo.nl.

38. Besselink MG, van Santvoort HC, Buskens E, Boermeester MA, van Goor H, Timmerman HM, Nieuwenhuijs VB, Bollen TL, van Ramshorst B, Witteman BJ, Rosman C, Ploeg RJ, Brink MA, Schaapherder AF, Dejong CH, Wahab PJ, van Laarhoven CJ, van der Harst E, van Eijck CH, Cuesta MA, Akkermans LM, Gooszen HG, Dutch Acute Pancreatitis Study Group: Probiotic prophylaxis in predicted severe acute pancreatitis: a randomised, double-blind, placebo-controlled trial. Lancet 2008, 371:651-659.

39. van Santvoort HC, Besselink MG, Bakker OJ, Hofker HS, Boermeester MA, Dejong $\mathrm{CH}$, van Goor $\mathrm{H}$, Schaapherder AF, van Eijck $\mathrm{CH}$, Bollen $\mathrm{TL}$, van Ramshorst B, Nieuwenhuijs VB, Timmer R, Laméris JS, Kruyt PM, Manusama ER, van der Harst E, van der Schelling GP, Karsten T, Hesselink EJ, van Laarhoven CJ, Rosman C, Bosscha K, de Wit RJ, Houdijk AP, van Leeuwen MS, Buskens E, Gooszen HG, Dutch Pancreatitis Study Group: A step-up approach or open necrosectomy for necrotizing pancreatitis. N Engl J Med 2010, 362:1491-1502.

40. Ellenberg SS, Fleming TR, de Mets DL: Data Monitoring Committees in Clinical Trials. Chichester: Wiley; 2002.

41. Reinders JS, Goud A, Timmer R, Kruyt PM, Witteman BJ, Smakman N, Breumelhof R, Donkervoort SC, Jansen JM, Heisterkamp J, Grubben M, van Ramshorst B, Boerma D: Early laparoscopic cholecystectomy improves outcomes after endoscopic sphincterotomy for choledochocystolithiasis. Gastroenterology 2010, 138:2315-2320.

42. Hazzan D, Geron N, Golijanin D, Reissman P, Shiloni E: Laparoscopic cholecystectomy in octogenarians. Surg Endosc 2003, 17:773-776.

43. Leandros E, Alexakis N, Archontovasilis F, Albanopoulos K, Dardamanis D, Menenakos E, Tsigris C, Giannopoulos A: Outcome analysis of laparoscopic cholecystectomy in patients aged 80 years and older with complicated gallstone disease. J Laparoendosc Adv Surg Tech A 2007, 17:731-735.

doi:10.1186/1745-6215-13-225

Cite this article as: Bouwense et al:: Pancreatitis of biliary origin, optimal timing of cholecystectomy (PONCHO trial): study protocol for a randomized controlled trial. Trials 2012 13:225.

\section{Submit your next manuscript to BioMed Central and take full advantage of:}

- Convenient online submission

- Thorough peer review

- No space constraints or color figure charges

- Immediate publication on acceptance

- Inclusion in PubMed, CAS, Scopus and Google Scholar

- Research which is freely available for redistribution

Submit your manuscript at www.biomedcentral.com/submit
C) Biomed Central 